\title{
DE90 010708
}

Analysis of the VENUS-3 Experiments

\author{
R. E. Mà̀rker \\ Oak Ridge National Laboratory \\ P.O. Box 2008, Oak Ridge, TN 37831-6364 \\ P. D'hondt, L. Leenders, A. Fabry \\ SCK/CEN Mol, Belgium \\ Paper to be given at the Seventh ASTM-EURATOM \\ Symposium on Reactor Dosimetry \\ Strasbourg, France
}

August 27-31, 1990

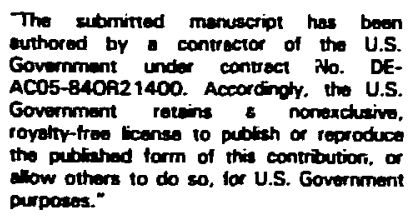

purposes."

"Research sponsored by Nuclear Regulatory Commission, U.S. Department of Energy under Contract No. DE-AC05-84OR21400 with Martin Marietta Energy Systems, Inc. 
ANALYSIS OF THE VENUS -3 EXPERIMENTS

ANALYSIS OF THE VENUS- 3 EXPERIMENTS

R. E. Maerker

Dak Ridge National Laboratory

Dak Ridge, Tennessee 37831-6364, USA

P. D'hondt, I. Leenders, A. Fabry

SCK/CEN Mol, Belgium

The results of applying a hybrid superpositionsynthesis calculational method to a mockup of a threedimensional geometry involving a partial length shield assembly at the VENUS-3 facility in Mol, Belgium, are described. Comparisons of iransport calculations us ing the method and many measurements involving nickel, indium, and aluminum dosimeters indicare agreement usually to within measurement uncertainties estimated at around $5 \%$, if effects of inaccuracies in the dosimeter cross sections are minimiz and proper orientation of the coordinate system used in the synthesis procedure is observed. These conclusions suggest a solution to the problem of predicting pressure vessel fluence in reactors modified by these partial-length shield assemblies may already exist.

\section{INTRODUCTION AND BACKGROUND}

Over the past several years, pressurized thermal shock (PTS) programs have become operational at many reactors in the United States. Since PTS-induced pressure vessel damage is dependent on the accumulated fluence, these programs are mainly concerned with reducing fluence rates incident on critical locations in the pressure vessel (PV) of pressurized water reactors (PWR's). At least two independent methods have been used, and both involve altering the core-source distribution. The first changes the refueling pattern to an in-in-out rotation at the critical azimuths so that twice-burned fuel now appears in the peripheral 
assemblies at those azimuths for which accumulated PV fluences have been the highest. This revised fuel loading scheme typically reduces the core leakage at these azimuths by about a factor of two. For many reactors of moderate age, this reduction is adequate to meet the additional requirements of plant-life extension. A second method is being used in several of the older reactors where fluence-rate reduction factors greater that those afforded by the first method have been deemed necessary. This procedure partially replaces the oxide fuel with metallic rods for those peripheral assemblies again located at the critical orientations. This substitution extends axially ove: a region that depends on the specific plant design, but covers in particular the most critical weld locations which are subject to PTS phenomena. The reduction in the fluence rates at the critcal locations for the latter case is of the order of a factor of ten, and is due principally to the complete removal of the fission source in the critical peripheral assemblies.

One older reactor that has been subjected to both methods of core-leakage reduction has been H.B. Robinson Unit 2, which underwent a revised fuel shuffling scheme for cycle 9 and the. introduction of partial-length shield assemblies (PLSA's) consisting of steel rods for cycle 10 and beyond. The analysis of cycle 9 using the LEPRICON procedure appears in the literature and is relatively straightforward(1). However, the use of the PLSA's introduces a geometrical complication that has not existed heretofore in conventional PV transport analysis, and a procedure should first be sought that adequately approximates the results of this three-dimensional transport with calculations involving only the one- and two-dimensional codes already in use.

Accordingly, an agreement was struck between the Nuclear Regulatory Commission (USNRC) and Mol which served the needs of both parties: The USNRC, with the approval of the Electric Power Research Institute, made available LEPRICON software for Mol to use in the dosimetry analysis of their DOEL reactors, while Mol agreed to perform experiments involving a PLSA mockup in their VENUS facility to serve to benchmark the calculational methods. The USNRC, through a contractual agreement with Oak Ridge National Laboratory (ORNL), also agreed to provide the results of an introductory analysis of these measurements.

\section{THE VENUS-3 FACILITY AND THE MEASUREMENTS ANALYZED}

The conclusions drawn from a meeting between ORNL and Mol scientists in January 1987 resulted in a design for VENUS-3 in which steel rods were substituted for the fuel over the complete lower half of the pins in the outermost five rows of two diametrically opposite arms of the cross. In FIg. I the PLSA modifications 


\section{ANALYSIS OF THE VENUS- 3 EXPERIMENTS}

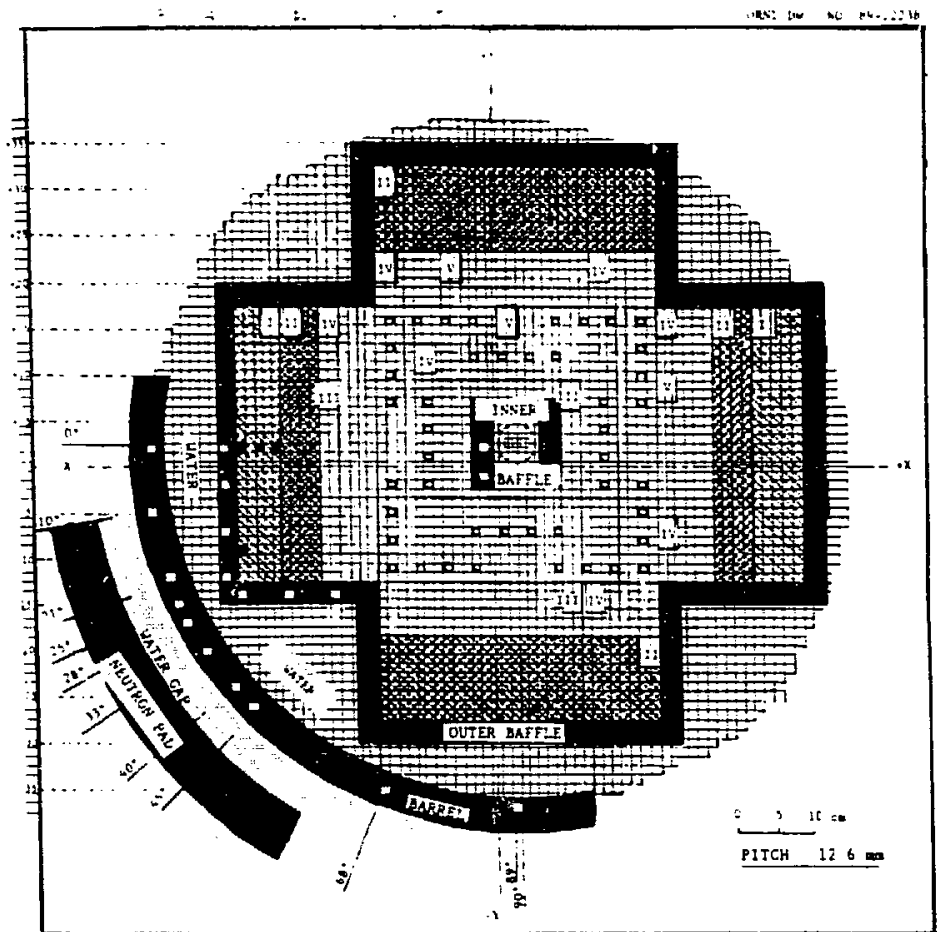

Fig. 1. Plan view of the VENUS-? facility showing the location of the nickel dosimeters used in the early run of March 1988 as the white squares and the four black squares in the PLSA.

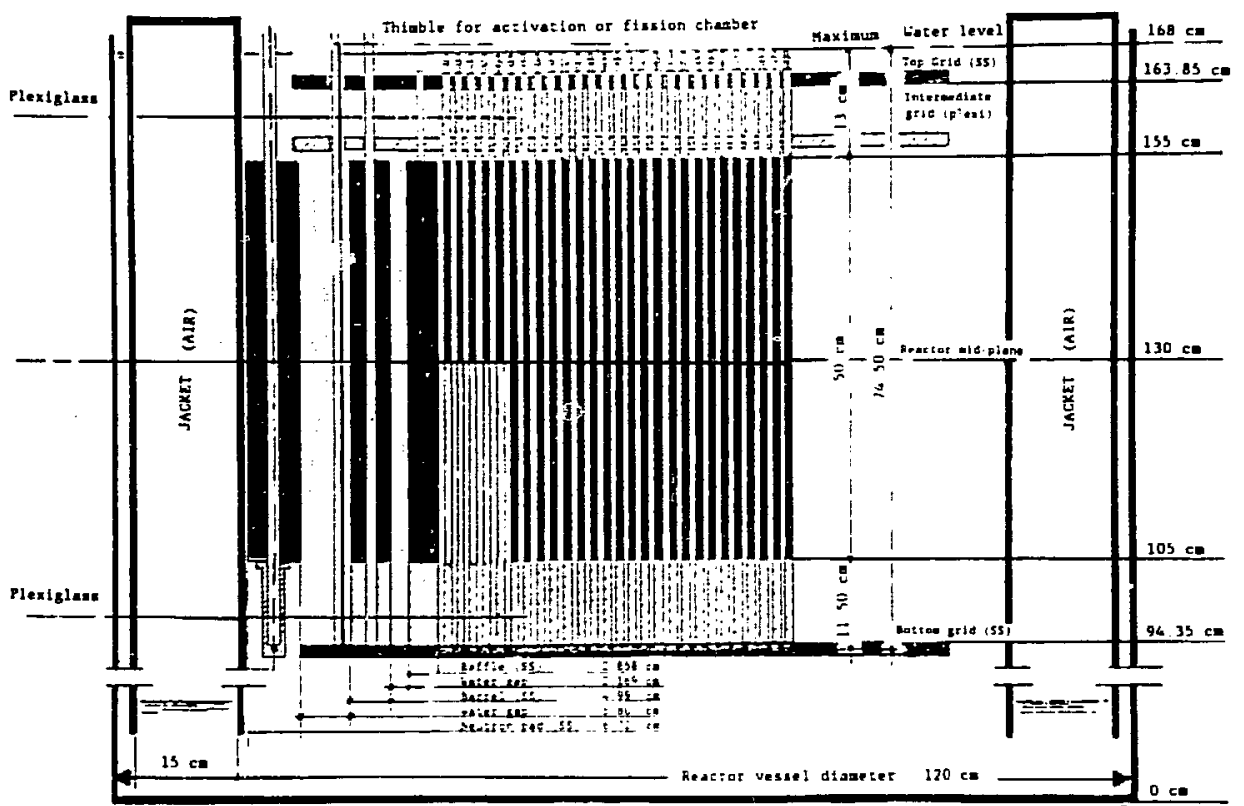

Fig. 2. Elevation vjew of the VENUS-3 facility showing the substitution of stainless steel rods for oxide fuel in the lower halves of five peripheral pins. 


\section{ANALYSIS OF THE VENUS - 3 EXPERIMENTS}

are indicated as the left- and right-hand arms. An elevation view of the full arrangement is shown in Fig. 2. The upper half of these assemblies as well as all the remaining pins contain fuel without modification. The core, however, was modified to employ 48 enriched 2350 in steel clad pins in the inner zone and 3.38 enriched $235 \mathrm{U}$ in zircalloy clad pins in the outer zone. Criticality was achieved by adjusting $a$ different number and arrangement of pyrex rods surrounding the core inner baffle than those in earlier VENUS configurations.

Since the focus of the VENUS-3 experiments is essentially on providing data to test transport methods for calculating ex-core fluence rates, the source description used in the calculations was taken from measurements in order to reduce this potential source of uncertainty as much as possible. The measurements consisted of obtaining a relative pin-by-pin, three-dimensional distribution of the fission source over one-quarter of the core using a gamma-ray scanning technique, and then following up with a normalization factor that would link this relative distribution to the absolute distribution existing during the runs involving the dosimetry exposures. The fuel-pin scans were performed at fine enough spatial intervals that interpolation between measured values was estimated to be accurate to within 5\%; the relative individual measurements were estimated to be accurate to within 28. Absolute measurements of the core fission rates at several locations using four different methods yielded an averaged value of $8.60 \times 10^{9} \pm 2.38$ (2) as the multiplicative factor for converting the source, arbitrarily normalized in the calculations to 1 fission/s per pin averaged over the core, to the source at full power. Measured reaction rates available for the present analysis involved the $58 \mathrm{Ni}(n, p), 115 \operatorname{In}\left(n, n^{\prime}\right)$, and $27 \mathrm{Al}(n, \alpha)$ dosimeters at various axial levels and several horizontal locations throughout the configuration. These measurements are believed to have an accuracy of better than 3\%. In this paper, explicit comparisons between calculated and measured values will be limited to those locations indicated by the white squares in the core barrel in Fig. 1 for the nickel dosimeters used in the early run of March 1988. This choice covers a large range of locations, starting at $0^{\circ}$ behind the PLSA mockup and continuing around to $90^{\circ}$ behind the unmodified assembly.

\section{DESCRIPTION OF THE CALCULATIONS}

The method chosen for the calculations is a modification of a fiuence-rate synthesis procedure often used in more conventional geometry(3,4). By decomposing the usual synthesis prescription into two components, one contribution arising from sources (A) lying above the PLSA region and the other from sources (B) lying within the levels defined by the PLSA region, one can write the 


\section{ANALYSIS OF THE VENUS - 3 EXPERIMENTS}

superposition-synthesis equation as

$$
\phi_{g}(X, Y, Z)=\frac{\phi_{g}^{A}(X, Y) \phi_{g}^{A}(X, Z)}{\phi_{g}^{A}(X)}+\frac{\phi_{g}^{B}(X, Y) \phi_{g}^{B}(X, Z)}{\phi_{g}^{B}(X)},
$$

where $\mathrm{X}$ is the principal direction of transport, $\mathrm{Y}$ is the transverse direction, and $Z$ is the axial direction. (5)

The sources to be used in the one- and two-dimensional discrete ordinates calculations are

$S_{g}^{A}(X, Y)=\int_{Z_{U I}}^{\infty} S_{g}(X, Y, Z) d Z$,

$S_{g}^{A}(X, Z)=\int_{-\infty}^{\infty} S_{g}\left(X, Y, Z \geq Z_{U L}\right) d Y$,

$S_{g}^{A}(X)=\int_{-\infty}^{\infty} d Y \int_{Z_{U L}}^{\infty} S_{B}(X, Y, Z) d Z$,

where $Z_{\mathrm{UL}}$ is in general the upper level to which the metal rods extend. For VENUS -3 , this is the midplane.

The condition that should be met for validity of. the method is that the fluence rate due to each component be separable in $Y$ and $Z$ over the spatial region where that component dominates. In the transport geometry using sources defined by Eqs (2) and (6), the core periphery is composed entirely of active pins, while in the geometry defined by Eqs (3) and (7) the outer five rows (in VENUS-3) contain only steel-filled pins.

\section{COMPARISON OF CALGULATED AND MEASURED RESULTS}

The measurements and calculations were originally expressed as reaction rates in units of reactions/s per target nucleus at full power. Comparisons are more meaningful when expressed in terms of equivalent fission fluence rates in the present application, however, for they remove some of the dependence of the calculated results on the dosimeter cross sections and of the measured results on reaction-specific parameters such as branching ratios. Thus, these resulting comparisons tend to become better measures of the accuracy of the calculational method itself, which is the primary goal of the VENUS-3 program. These equivalent fission fluence rates are reaction dependent, and are defined for reaction $i$ as

$$
\phi_{1}=\frac{\int_{0}^{\infty} \phi(E) \sigma_{1}(E) d E}{\int_{0}^{\infty} 235 x(E) \sigma_{1}(E) d E},
$$




\section{ANALYSIS OF THE VENUS-3 EXPERIMENTS}

where the numerator is the conventional reaction rate and the denominator is the spectrum-averaged reaction cross section in a 2350 fission field. For all three reactions analyzed, calculated values of the denominator using the cross-section library adopted for this analysis(6) underestimate the measured values used by Mol by 3 to $58 .(7)$

The calculations described so far involve an $X Y$ run, an $X Z$ run, and an $X$ run, all for each of the two source components, for a total of six discrete ordinates calculations. It is to be expected, however, that the two measurements in the core barrel at $68^{\circ}$ and $89^{\circ}$ (or any such similar locations requiring a considerable re-orientation of the coordinate system defined in Eqs (1) through (7) and Fig. 1) may not be well calculated. As pointed out earlier, the significance of the $X$ and $Y$ axes in these equations is in their interpretation as parallel and perpendicular to the principal direction of flow to the detector, respectively. This direction can be approximated in the present geometry for ex-core detectors by a line joining the core center and the detector. For most of the detectors shown in Fig. 1, both in-core and ex-core, the $\mathrm{XY}$ coordinate system shown in Fig. 1 is adequate. For detector locations lying at angles greater than $45^{\circ}$ with the $\mathrm{X}$-axis, $\mathrm{X}$ and $Y$ may be interchanged in Eqs (1) through (7) and the resulting sources resummed. This has no effect on the $X Y$ transport calculations if $X$ and $Y$ are now reinterpreted as the old $Y$ and $X$ respectively, and the original $X Y$ results are still valid. The $X Z$ and $X$ transport calculations must be redone, however, since their source terms are now different. This results in additional $X Z$ and $X$ runs for each of the two source components. A grand total of ten discrete ortinates calculations were thus made. The reaction rates at $68^{\circ}$ and $89^{\circ}$ that were calculated using the re-oriented coordinate system provide good reference points for confirming the accuracy of the synthesis procedure in the vicinity of an unmodified assembly, where no consideration of separate source components (i.e., superposition) is necessary.

Some comparisons of the nickel fluence rates in the core barrel are shown in Table 1 . Values of $\mathrm{C} / \mathrm{E}$ at similar locations to those in Table 1 for the indium and aluminum dosimeters are virtually the same, thus extending verification of the method to higher and lower energies. Comparisons at other locations, both in-core and ex-core, some of which are indicated as additional white squares along with a few black squares in Fig. 1, further substantiate the general applicability of the method. The comparisons at most locations agree to within the estimated standard deviation of around $5 \%$ which is a composite of ail measurement uncertainties. 
ANALYSIS OF THE VENUS - 3 EXPERIMENTS

Table 1. Some Absolute Comparisons of the Nickel Fluence Rates in the Core Bartel for the March 1988 Run

\begin{tabular}{|c|c|c|c|c|c|c|c|c|}
\hline$\frac{2}{(c \pi)^{a}}$ & Angle $e^{b}$ & $\phi_{I}$ & de & $\phi_{e} / \phi_{z}$ & Arigle & $\phi_{I}$ & $\phi=$ & $\phi_{c} / \dot{\phi}_{I}$ \\
\hline $\begin{array}{l}106.5 \\
114.5 \\
122.5 \\
128.5 \\
131.5 \\
134.5 \\
141.5 \\
145.5 \\
149.5 \\
153.5\end{array}$ & 0 deg & $\begin{array}{l}1.70+7 \\
2.83+7 \\
4.39+7 \\
5.54+7 \\
6.09+7 \\
6.45+7 \\
6.44+7 \\
5.87+7 \\
4.94+7 \\
3.76+7 \\
\end{array}$ & $\begin{array}{l}1.64+7 \mathrm{~d} \\
2.80+7 \\
4.07+7 \\
5.31+7 \\
5.64+7 \\
6.05+7 \\
6.05+7 \\
5.55+7 \\
4.75+7 \\
3.62+7 \\
\end{array}$ & $\begin{array}{l}0.96 \\
0.99 \\
0.93 \\
0.96 \\
0.93 \\
0.94 \\
0.94 \\
0.95 \\
0.96 \\
0.96 \\
\end{array}$ & 21 deg & $\begin{array}{l}1.41+7 \\
2.39+7 \\
3.56+7 \\
4.54+7 \\
5.03+7 \\
5.41+7 \\
5.35+7 \\
4.78+7 \\
4.05+7 \\
3.07+7\end{array}$ & $\begin{array}{l}1.40+7^{\mathrm{d}} \\
2.37+7 \\
3.46+7 \\
4.48+7 \\
4.80+7 \\
5.24+7 \\
5.16+7 \\
4.67+7 \\
3.96+7 \\
2.95+7\end{array}$ & $\begin{array}{l}0.99 \\
0.99 \\
0.97 \\
0.99 \\
0.95 \\
0.97 \\
0.96 \\
0.98 \\
0.98 \\
0.96\end{array}$ \\
\hline $\begin{array}{l}106.5 \\
114.5 \\
122.5 \\
128.5 \\
131.5 \\
134.5 \\
141.5 \\
145.5 \\
149.5 \\
153.5 \\
\end{array}$ & $45 \mathrm{deg}$ & $\begin{array}{l}1.75+7 \\
2.74+7 \\
3.53+7 \\
3.84+7 \\
3.86+7 \\
3.83+7 \\
3.50+7 \\
3.09+7 \\
2.54+7 \\
1.97+7\end{array}$ & $\begin{array}{l}1.77+7 \\
2.96+7 \\
3.87+7 \\
4.30+7 \\
4.53+7 \\
4.53+7 \\
4.02+7 \\
3.48+7 \\
2.81+7 \\
2.09+7 \\
\end{array}$ & $\begin{array}{l}1.01 \\
1.08 \\
1.10 \\
1.12 \\
1.17 \\
1.18 \\
1.15 \\
1.13 \\
1.11 \\
1.06\end{array}$ & $68 \mathrm{deg}$ & $\begin{array}{l}3.42+7 \\
5.72+7 \\
7.09+7 \\
7.51+7 \\
7.68+7 \\
7.50+7 \\
6.64+7 \\
5.72+7 \\
4.67+7 \\
3.45+7\end{array}$ & $\begin{array}{l}3.24+7^{e} \\
5.50+7 \\
7.00+7 \\
7.51+7 \\
7.53+7 \\
7.40+7 \\
6.50+7 \\
5.65+7 \\
4.67+7 \\
3.43+7\end{array}$ & $\begin{array}{l}0.95 \\
0.96 \\
0.99 \\
1.00 \\
0.98 \\
0.99 \\
0.98 \\
0.09 \\
1.00 \\
0.09\end{array}$ \\
\hline $\begin{array}{l}106.5 \\
114.5 \\
122.5 \\
128.5 \\
131.5 \\
134.5 \\
141.5 \\
145.5 \\
149.5 \\
153.5 \\
\end{array}$ & $89 \mathrm{deg}$ & $\begin{array}{l}4.32+7 \\
7.08+7 \\
8.94+7 \\
9.54+7 \\
9.63+7 \\
9.45+7 \\
8.21+7 \\
7.17+7 \\
5.81+7 \\
4.32+7 \\
\end{array}$ & $\begin{array}{l}4.60+7^{d} \\
7.82+7 \\
1.02+8 \\
1.09+8 \\
1.09+8 \\
1.07+9 \\
9.36+7 \\
8.05+7 \\
6.49+7 \\
4.78+7 \\
\end{array}$ & $\begin{array}{l}1.06 \\
1.10 \\
1.14 \\
1.14 \\
1.13 \\
1.13 \\
1.14 \\
1.12 \\
1.12 \\
1.11 \\
\end{array}$ & P9 deg & $\begin{array}{l}4.32+7 \\
7.08+7 \\
8 \cdot 94+7 \\
9.54+7 \\
9.63+7 \\
9 \cdot 45+7 \\
8.21+7 \\
7.17+7 \\
5 \cdot 81+7 \\
4.32+7\end{array}$ & $\begin{array}{l}4.23+7^{\mathrm{e}} \\
7.00+7 \\
8.85+7 \\
9.46+7 \\
9.55+7 \\
9.26+7 \\
8.14+7 \\
7.14+7 \\
5.92+7 \\
4.39+7\end{array}$ & $\begin{array}{l}0.98 \\
0.99 \\
0.99 \\
0.99 \\
0.99 \\
0.98 \\
0.99 \\
1.00 \\
1.02 \\
1.02\end{array}$ \\
\hline $\begin{array}{l}114.5 \\
131.5 \\
145.5 \\
\end{array}$ & $10 \mathrm{deg}$ & $\begin{array}{l}2.48+7 \\
5.21+7 \\
5.04+7\end{array}$ & $\begin{array}{l}2.44+7^{a} \\
4.86+7 \\
4.76+7 \\
\end{array}$ & $\begin{array}{l}0.98 \\
0.93 \\
0.94 \\
\end{array}$ & 25 deg & $\begin{array}{l}2.18+7 \\
4.35+7 \\
4.09+7\end{array}$ & $\begin{array}{l}2.17+7 \\
4.25+7 \\
4.07+7\end{array}$ & $\begin{array}{l}1.00 \\
0.98 \\
1.00\end{array}$ \\
\hline $\begin{array}{l}114.5 \\
131.5 \\
145.5\end{array}$ & $33 \mathrm{deg}$ & $\begin{array}{l}2.88+7 \\
4.48+7 \\
3.93+7\end{array}$ & $\begin{array}{l}2.31+7^{d} \\
4.22+7 \\
3.80+7\end{array}$ & $\begin{array}{l}0.80 \\
0.94 \\
0.97\end{array}$ & $40 \mathrm{deg}$ & $\begin{array}{l}2.53+7 \\
3.76+7 \\
3.06+7\end{array}$ & $\begin{array}{l}2.38+7^{d} \\
4.34+7 \\
3.62+7\end{array}$ & $\begin{array}{l}0.94 \\
1.15 \\
1.18\end{array}$ \\
\hline
\end{tabular}

The pins extend from 105 to $155 \mathrm{~cm}$; the PLSA extends from 105 to $130 \mathrm{~cm}$. See Fig 2.

See Eig. 1.

Read as $1.70 \times 10^{7} \mathrm{n} / \mathrm{cm}^{2} \cdot \mathrm{s}$ at full power.

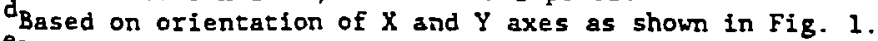

Based on orfentation of $X$ and $Y$ axes rotated 90 deg counterclockwise to those of Fig. 1 .

\section{DISCUSSION OF THE RESULTS AND CONCLUSIONS}

Success in the introduction of a source decomposition and superposition technique and combining it with a fluence-rate synthesis procedure is conclusively demonstrated by the axial comparisons at the $0^{\circ}, 10^{\circ}, 21^{\circ}, 25^{\circ}, 28^{\circ}$, and $33^{\circ}$ locations in the core barrel as well as four PLSA locations, the water gap, and all seven locations in the outer baffle. The axial profiles at these locations are influenced by the PLSA and are asymmetric, as contrasted with the nearly perfect symmetry of the profiles 
ANALYSIS OF THE VENUS-3 EXPERIMENTS

located well inside the core and in the vicinity of the $68^{\circ}$ and $89^{\circ}$ core barrel locations. A legitimate conclusion deduced from the comparisons near $0^{\circ}$ and $89^{\circ}$ is that, at least for VENUS-3, Eqs (1) through (7) are as accurate in the treatment of PLSA-affected regions as earlier equations without source decomposition are in the unaffected ones. It is only at the two locations in the vicinity of $45^{\circ}$ in the core barrel that any significant error is incurred with the proposed technique, and presumably this error could be reduced by reorienting the $X$ and $Y$ axes in Eqs (2) through (7) to 1 ie at $45^{\circ}$ to the directions shown in Fig. 1, were it really necessary. The error near $45^{\circ}$ is still not large, however, being at most 188 (see Table 1). The conclusion that the method provides acceptable accuracy when applied to VENUS-3 does not necessarily imply that comparable accuracies should be realized when applied to PWR's. Differences in geometry between VENUS -3 and H.B. Robinson- 2 are still considerable. Nevertheless, the accuracy of the proposed method when applied to VENUS- 3 is very encouraging, and suggests that a relatively simple modification to the method, if necessary, could be found for application to PWR's.

\section{REFERENCES}

1. R. E. Maerker, "LEPRICON Analysis of Pressure Vessel Surveillance Dosimetry Inserted into H.B. Robinson-2 During Cycle 9," Nucl. Sci. \& Eng. 96, 4,263 (1987).

2. L. Verbruggen, LWR-PVS Benchmark Experiment VENUS-3. Part 3 . Absolute Core Power, FCP/VEN/03, Mol, (December 1989).

3. G. P. Cavanaugh, Summary Meeting on PCA Blind Test, National Bureau of Standards (1983).

4. R. E. Maerker, M. L. Williams, and B. L. Broadhead, "Accounting for Changing Source Distributions in Light Water Reactor Surveillance Dosimetry Analysis," Nucl. Sci.\& Eng. 94, 4, 291 (1986).

5. M. L. Williams, et al., H.B. Robinson Fluence Reduction Analysis for the PLSA Concept, TEC Report R-83-030, Technology for Energy Corporation and Carolina Power and Light Company (1983).

6. M. L. Williams, et al., The ELXSIR Cross-Section Library for LWR Pressure Vesse1 Irradiation Studies: Part of the LEPRICON Computer Code System, EPRI NP-3654 (September 1984).

7. R. E. Maerker, Analysis of the VENUS-3 Experiments, Oak Ridge National Latoratory, NUREG/CR-5338, ORNL/TM-11106, p.54 (1989). 